Thus any benefit of anticoagulants is likely to be modest, and a large randomised trial would be required to detect it reliably. Of course, any modest benefit would be offset by the complexity, side effects, and cost of the treatment; in any case, a rather small population of patients with stroke are eligible for such treatment. ${ }^{12}$ On the other hand, our negative results, based on a non-randomised comparison and with fairly wide confidence intervals, are unlikely to convince doctors who are already using long term anticoagulant treatment despite the lack of good data to support their opinion. To resolve this dilemma we are planning a three year randomised trial of 1200 patients to compare treatment with anticoagulants, aspirin, and placebo.

The Oxfordshire community stroke project is funded by the British Medical Research Council and the Chest, Heart, and Stroke Association. The Dutch Heart Foundation supported JL during a visit to Oxford for three months.

\section{References}

1 Furlan AS, Cavalier SJ, Hobbs RE, et al. Hemorrhage and anticoagulation after non-septic embolic brain infarction. Neurology 1982;32:280-2.

2 Cerebral Embolism Study Group. Immediate anticoagulation of embolic stroke: a randomized trial. Stroke 1983;14:668-76.
3 Lodder J, van der Lugt PJM. Evaluation of the risk of immediate anticoagulant treatment in patients with embolic stroke of cardiac origin. Stroke 1983;14:42-6.

4 Kelley RE, Berger JR, Alter M, et al. Cerebral ischemia and atrial fibrillation: prospective study. Neurology 1984;34:1285-91.

5 Martin GJ, Biller J. Non-septic cerebral emboli of cardiac origin. Arch Intern Med 1984;144: $1997-9$.

6 Starkey I, Warlow CP. The secondary prevention of stroke in patients with atrial fibrillation. Arch Neurol 1986;43:66-8.

7 Sherman OG, Hart RG, Easton JD. The secondary prevention of stroke in patients with atria fibrillation. Arch Neurol 1986;43:68-70.

8 Hachinski V. Atrial fibrillation and recurrent stroke. Arch Neurol 1986;43:70.

9 Koller RL. Recurrent embolic cerebral infarction and anticoagulation. Neurology 1982;32:283-5. 0 Norving B, Nilsson B. Cerebral embolism of cardiac origin; the limited possibilities of secondary prevention. Acta Neurol Scand 1986;73:520.

1 Gustafsson C, Britton M. Prognosis after brain infarction in patients with non-valvular atria fibrillation compared with sinus rhythm. Acta Neurol Scand 1986;73:520-1.

12 Sandercock P, Bamford J, Warlow C, Peto R, Starkey I. Is a controlled trial of long-term ora anticoagulants in patients with stroke and non-rheumatic atrial fibrillation worthwhile? Lance 1986;i:788-92.

13 Lodder J. A prospective study on the risk of immediate anticoagulation in cardiac embolic stroke. In: Stober T, Schimrigh K, Ganten D, Sherman D, eds. Central nervous system control of the heart. Boston: Martinus Nijhoff, 1986:245-8.

14 Oxfordshire Community Stroke Project. Incidence of stroke in Oxfordshire: first year's experience of a community stroke register. BrMed f 1983;287:713-7.

15 Peto R, Pike MC, Armitage $P$, et al. Design and analysis of randomized clinical trials requiring prolonged observation of each patient. II. Analysis and samples. Brf Cancer 1977;35:1-39.

16 Pessin MS, Hinton RC, Davis KR. Mechanisms of acute carotid stroke. Arch Neurol 1979;6: 245-52.

7 Yusuf S, Peto R, Lewis J, Collins R, Sleight P. Beta blockade during and after myocardia infarction: an overview of the randomized trials. Prog Cardiovasc Dis 1985;27:335-71.

18 Sage JI, Van Uitert RL. Risk of recurrent stroke in patients with atrial fibrillation and non-valvular heart disease. Stroke 1983:14:537-40.

(Accepted 16 December 1987)

\title{
Respiratory illness and home environment of ethnic groups
}

\author{
R J W MELIA, S CHINN, R J RONA
}

\begin{abstract}
Factors contributing to differences in the prevalences of respiratory symptoms and diseases among ethnic groups were studied in primary schoolchildren living in 20 inner city areas of England in 1983. The raised prevalences of respiratory symptoms in these groups were compared with results from a national representative sample of children studied in 1982. Data on age, sex, respiratory illness, and social and environmental variables were obtained by questionnaire for 4815 children living in inner cities. The children were classified as white, Afro-Caribbean, Urdu, Gujarati, Punjabi, other Asian, or "other." Significant differences in the prevalence of respiratory conditions were found among the ethnic groups after allowance was made for the effects of interfering variables. Except for asthma all conditions were most prevalent in Afro-Caribbeans and whites. In these two ethnic groups respiratory illness was significantly associated with belonging to a one parent family and the combined use of gas cookers and paraffin heaters at home.

Respiratory illness was found to vary in prevalence among ethnic groups but may be perceived differently by different groups. Further studies, measuring lung function, are necessary.
\end{abstract}

\footnotetext{
Department of Community Medicine, United Medical and Dental Schools of Guy's and St Thomas's Hospitals, London SE1 7EH

R J W MELIA, PHD, lecturer in epidemiology

$S$ CHINN, MA, senior lecturer in medical statistics

R J RONA, PHD, MFCM, senior lecturer in community medicine

Correspondence to: Dr Melia.
}

\section{Introduction}

The health of ethnic minority groups in the United Kingdom has been the subject of considerable discussion and concern during the past two decades. Inherited disorders such as sickle cell anaemia and illnesses such as rickets have been highlighted. ${ }^{12}$ Respiratory health has not been studied thoroughly, though a higher prevalence of respiratory illness has been reported in West Indians $s^{34}$ and respiratory illness in infants was reported to be more common among Bengalis than the indigenous population of an inner city area. ${ }^{5}$ The cause of these differences has not been studied in detail, although poor social circumstances are probably a factor in some ethnic groups, As respiratory disease in childhood has been linked with susceptibility to respiratory disease in later $\operatorname{life}^{6}$ it is important to investigate the causes of variation in respiratory health between children of different ethnic groups to identify preventive measures.

This study of primary schoolchildren investigated the prevalence of respiratory illness in ethnic groups in inner city areas and factors that contribute to differences in prevalence among the ethnic groups and between the groups from inner cities and a national sample of children.

\section{Subjects and methods}

In 1983 data on respiratory symptoms and diseases were collected in the national study of health and growth, a surveillance study of primary schoolchildren that included white, Afro-Caribbean, Indian, and Pakistani children from inner city areas, ${ }^{7}$ most of whom had spent most of their lives in Britain. Twenty wards in England with a high percentage of children of Afro-Caribbean and Indo-Pakistani ethnic origin and children living in inner city areas with a high level of overcrowding, unemployment, or lack of exclusive use of amenities had been selected, and about 350 children aged 5-11 from one or two schools close to the geographical centre of each ward had been studied. In 1983 the study investigated ethnic minorities for the first time. Several factors were studied in connection with respiratory disease but smoking was not one of them. To assess further the size of the 
problem of respiratory disease in inner cities we included in our study data on white primary schoolchildren from the 1982 national study of health and growth; these children had a similar social class distribution to other representative national samples. ${ }^{78}$ The methods of collecting data closely resembled those used in 1983, although data on "colds going to the chest" were not collected.

In 1983 data on respiratory illness in the children were collected from a questionnaire completed by a parent of each child. The questionnaire was available in English, English and Urdu, English and Gujarati, and English and Punjabi. It asked whether the child usually had a cough first thing in the morning, cough during the day or night, or colds that "went to the chest"; whether the child's chest ever sounded wheezy or whistling; and how many attacks of bronchitis or asthma had been experienced during the past 12 months. Other questions were asked about the number of children at home, father's occupation, mother's educational attainment, uptake of free school meals, and types of fuel used for cooking and heating at home. Ethnic group was ascertained from assessments made by fieldworkers and the main language spoken at home.

Prevalences of respiratory conditions were compared with the $\chi^{2}$ test and by logistic regression using the computer program GLIM. ${ }^{9}$ As the respiratory conditions were interrelated an overall measure of respiratory illness (the presence of one or more respiratory conditions) was also used. Two main groups of regression analyses were carried out on the 1983 sample. Firstly, ethnic groups were compared allowing for age, sex, area of residence, mother's educational attainment, and number of children at home. Area of residence was included as the ethnic minority groups came mainly from the areas specifically selected to include those groups ${ }^{7}$ and the prevalence of respiratory illness in children might be related to environmental factors not otherwise considered in our analyses. Mother's educational attainment, classified into three groups (no formal education or primary only; primary and secondary; college or university), was used instead of social class to indicate social circumstances. Secondly, for whites and Afro-Caribbeans the additional effects of living in a one parent family and living in a home with a gas cooker or paraffin heaters were studied. Gas cookers and paraffin heaters are indoor sources of air pollution, particularly nitrogen dioxide. ${ }^{11}$ Homes were placed in one of three groups according to the expected level of nitrogen dioxide: homes with an electric cooker and no paraffin heaters, homes with a gas cooker and no paraffin heaters, and homes with both a gas cooker and paraffin heaters. Homes with paraffin heaters alone or with coal fires, another important source of indoor air pollution, were excluded because their numbers were too small. (Living in a one parent family and the effects of indoor air pollution could not be studied in the Asian groups because the question on one parent families had been incorrectly translated and too few homes had electric cookers or paraffin heaters (less than 15 and less than seven, respectively in each Asian group).)
Additional regression analyses were carried out to compare respiratory symptoms between white children studied in 1982 and 1983. The effects of age, sex, father's social class, living in a one parent family, mother's education, and number of children at home were allowed for in this comparison.

\section{Results}

Data on 4815 children $(67 \cdot 8 \%$ of the 7103 children in the 1983 sample) were obtained. Absence of data on age, sex, or ethnic group excluded 382 children, and absence of data on the six respiratory conditions, mother's education, or type of fuel used for cooking excluded a further 1906. The response rate varied among ethnic groups, with Afro-Caribbeans having a response rate of $58 \%$, Urdus $69 \%$, "other ethnic groups" $56 \%$, and each remaining group more than $70 \%$. The 2105 white children from the 1983 sample were compared with 4849 white children from the 1982 sample ( $70.7 \%$ of the 6862 studied). These samples were similar in their age and sex distributions.

Tables I and II show the unadjusted prevalences of respiratory symptoms and diseases in boys and girls studied in 1983 by ethnic group. The prevalence of all conditions except cough in the morning in both sexes and asthma in boys varied significantly among ethnic groups $(p<0.01)$. In both sexes cough during the day or night and colds going to the chest tended to be most prevalent in whites and Afro-Caribbeans. Bronchitis was most prevalent in whites, and wheezing in whites and Afro-Caribbeans. For the other respiratory conditions, differences in prevalence among ethnic groups were inconsistent between the sexes. The overall measure of respiratory illness, the presence of one or more respiratory conditions, was found most commonly in Afro-Caribbeans and least commonly in Gujaratis. The prevalences in whites were high not only compared with those in the other ethnic groups but also compared with those in the 1982 sample.

Each respiratory condition was analysed separately for the effects of age, sex, mother's education, number of children in family, and area of residence. The prevalence of all conditions except asthma declined significantly with age $(p<0.05)$ and tended to be higher in boys than girls. The prevalences showed some association with mother's education, tending to be highest among children of mothers with no formal education or anly elementary education and lowest among children whose mothers had been to college or university, but significantly so only for coughs $(p<0.05)$. The presence of four or more children in the family was associated with high prevalences of coughs $(p<0.05)$, but the other conditions were reported most commonly for single children $(p<0.05)$. Area of residence was related to the prevalence of cough in the morning, wheezing, and bronchitis $(p<0.05)$. The first order interactions among these independent variables on

TABLE I-Unadjusted percentage (number) of respiratory conditions by ethnic group among boys

\begin{tabular}{|c|c|c|c|c|c|c|c|c|c|}
\hline & \multicolumn{2}{|c|}{ White } & \multirow[b]{2}{*}{$\begin{array}{l}\text { Afro-Caribbean } \\
(n=261)\end{array}$} & \multirow[b]{2}{*}{$\underset{(\mathbf{n}=157)}{\text { Urdu }}$} & \multirow[b]{2}{*}{$\begin{array}{l}\text { Gujarati } \\
(\mathrm{n}=221)\end{array}$} & \multirow[b]{2}{*}{$\begin{array}{l}\text { Punjabi } \\
(\mathrm{n}=451)\end{array}$} & \multirow[b]{2}{*}{$\begin{array}{l}\text { Other Asian } \\
(\mathrm{n}=110)\end{array}$} & \multirow[b]{2}{*}{$\begin{array}{c}\text { Other } \\
(\mathrm{n}=140)\end{array}$} & \multirow{2}{*}{$\begin{array}{c}\text { Total } \\
(1983)^{\prime} \\
(\mathrm{n}=2429)\end{array}$} \\
\hline & $\begin{array}{c}1982 \\
(n=2497)\end{array}$ & $\begin{array}{c}1983 \\
(n=1089)\end{array}$ & & & & & & & \\
\hline $\begin{array}{l}\text { Cough in the morning } \\
\text { Cough during day or night } \\
\text { Wheezing } \\
\text { "Colds going to chest" } \\
\text { Bronchitis } \\
\text { Asthma } \\
\text { One or more respiratory conditions }\end{array}$ & $\begin{array}{r}3 \cdot 5(88) \\
7 \cdot 3(183) \\
11 \cdot 1(276)\end{array}$ & $\begin{array}{c}7 \cdot 7(84)^{\star} \\
15 \cdot 6(170)^{\star} \\
15 \cdot 5(169)^{\star} \\
34 \cdot 2(372) \\
7 \cdot 6(83)^{\star} \\
3 \cdot 5(38) \\
40 \cdot 9(445)\end{array}$ & $\begin{array}{r}8 \cdot 8(23) \\
18 \cdot 4(48) \\
14 \cdot 9(39) \\
33 \cdot 3(87) \\
3 \cdot 4 \quad(9) \\
1 \cdot 5(4) \\
41 \cdot 8(109)\end{array}$ & $\begin{array}{r}9 \cdot 6(15) \\
8 \cdot 9(14) \\
10 \cdot 2(16) \\
19 \cdot 7(31) \\
1 \cdot 3(2) \\
6 \cdot 4(10) \\
28 \cdot 0(44)\end{array}$ & $\begin{array}{r}3 \cdot 6(8) \\
8 \cdot 1(18) \\
5 \cdot 9(13) \\
17 \cdot 2(38) \\
1 \cdot 8(4) \\
2 \cdot 3(5) \\
23 \cdot 1(51)\end{array}$ & $\begin{aligned} & 8 \cdot 4(38) \\
& 10 \cdot 0(45) \\
& 10 \cdot 9(49) \\
& 21 \cdot 5(97) \\
& 3 \cdot 8(17) \\
& 4 \cdot 7(21) \\
& 28 \cdot 4(128)\end{aligned}$ & $\begin{array}{r}4 \cdot 5(5) \\
8 \cdot 2(9) \\
7 \cdot 3(8) \\
25 \cdot 5(28) \\
5 \cdot 5(6) \\
3 \cdot 6(4) \\
30 \cdot 0(33)\end{array}$ & $\begin{array}{r}3 \cdot 6(5) \\
9 \cdot 3(13) \\
10 \cdot 0(14) \\
26 \cdot 4(37) \\
2 \cdot 1(3) \\
5 \cdot 7(8) \\
33 \cdot 6(47)\end{array}$ & $\begin{array}{l}7 \cdot 3(178) \\
13 \cdot 1(317) \dagger \\
12 \cdot 7(308) \dagger \\
28 \cdot 4(690) \dagger \\
5 \cdot 1(124) \dagger \\
3 \cdot 7(90) \\
35 \cdot 3(857) \dagger\end{array}$ \\
\hline
\end{tabular}

*Whites, $1982 v 1983\left(\chi^{2}\right.$ test, $\left.\mathrm{df}=1\right): \mathrm{p}<0.001$.

tAll ethnic groups, $1983\left(\chi^{2}\right.$ test, $\left.\mathrm{df}=6\right): \mathrm{p}<0 \cdot 001$.

TABLE II-Unadjusted percentage (number) of respiratory conditions by ethnic group among girls

\begin{tabular}{|c|c|c|c|c|c|c|c|c|c|}
\hline & \multicolumn{2}{|c|}{ White } & \multirow[b]{2}{*}{$\begin{array}{l}\text { Afro-Caribbean } \\
(\mathrm{n}=284)\end{array}$} & \multirow[b]{2}{*}{$\underset{(n=166)}{\text { Urdu }}$} & \multirow[b]{2}{*}{$\begin{array}{l}\text { Gujarati } \\
(n=220)\end{array}$} & \multirow[b]{2}{*}{$\begin{array}{l}\text { Punjabi } \\
(n=436)\end{array}$} & \multirow[b]{2}{*}{$\begin{array}{c}\text { Other Asian } \\
(n=108)\end{array}$} & \multirow[b]{2}{*}{$\begin{array}{c}\text { Other } \\
(n=156)\end{array}$} & \multirow{2}{*}{$\begin{array}{c}\text { Total } \\
(1983) \\
(n=2386)\end{array}$} \\
\hline & $\begin{array}{c}1982 \\
(\mathrm{n}=2352)\end{array}$ & $\begin{array}{c}1983 \\
(n=1016)\end{array}$ & & & & & & & \\
\hline $\begin{array}{l}\text { Cough in morning } \\
\text { Cough during day or night } \\
\text { Wheezing } \\
\text { "Colds going to chest" } \\
\text { Bronchitis } \\
\text { Asthma } \\
\text { One or more respiratory conditions }\end{array}$ & $\begin{array}{l}3 \cdot 8(90) \\
6 \cdot 2(145) \\
8 \cdot 1(190) \\
2 \cdot 2(51) \\
1 \cdot 9(44)\end{array}$ & $\begin{array}{l}7 \cdot 3(74)^{\star \star} \\
15 \cdot 2(154)^{\star \star} \\
11 \cdot 6(118)^{\star} \\
32 \cdot 7(332) \\
5 \cdot 4(55)^{\star \star} \\
1 \cdot 1(11) \\
38 \cdot 2(388)\end{array}$ & $\begin{aligned} & 9 \cdot 9(28) \\
& 16 \cdot 5(47) \\
& 12 \cdot 0(34) \\
& 30 \cdot 6(87) \\
& 4 \cdot 2(12) \\
& 2 \cdot 1 \quad(6) \\
& 39 \cdot 1(111)\end{aligned}$ & $\begin{array}{r}4 \cdot 8(8) \\
9 \cdot 6(16) \\
12 \cdot 0(20) \\
15 \cdot 1(25) \\
0 \cdot 6(1) \\
3 \cdot 6(6) \\
24 \cdot 7(41)\end{array}$ & $\begin{array}{r}7 \cdot 3(16) \\
10 \cdot 5(23) \\
5 \cdot 5(12) \\
12 \cdot 7(28) \\
0 \cdot 9(2) \\
0 \cdot 5(1) \\
19 \cdot 1(42)\end{array}$ & $\begin{aligned} & 5 \cdot 5(24) \\
& 8 \cdot 5(37) \\
& 6 \cdot 7(29) \\
& 14 \cdot 7(64) \\
& 3 \cdot 0(13) \\
& 2 \cdot 5(11) \\
& 23 \cdot 2(101)\end{aligned}$ & $\begin{array}{r}10 \cdot 2(11) \\
13 \cdot 0(14) \\
5 \cdot 6(6) \\
21 \cdot 3(23) \\
0 \cdot 0(0) \\
4 \cdot 6(5) \\
26 \cdot 9(29)\end{array}$ & $\begin{array}{r}5 \cdot 1(8) \\
5 \cdot 1(8) \\
6 \cdot 4(10) \\
22 \cdot 4(35) \\
3 \cdot 8(6) \\
3 \cdot 8(6) \\
28 \cdot 8(45)\end{array}$ & $\begin{array}{l}7 \cdot 1(169) \\
12.5(299) \ddagger \\
9 \cdot 6(229) \dagger \\
24.9(594) \ddagger \\
3.7(89) \ddagger \\
1.9(46) \dagger \\
31 \cdot 7(757) \ddagger\end{array}$ \\
\hline
\end{tabular}

Whites, $1982 v 1983\left(\chi^{2}\right.$ test, $\left.\mathrm{df}=1\right):{ }^{\star} \mathrm{p}<0.01,{ }^{\star \star} \mathrm{p}<0.001$.

All ethnic groups, $1983\left(\chi^{2}\right.$ test, $\left.\mathrm{df}=6\right): \mathrm{tp}<0 \cdot 01, \neq \mathrm{p} \leqslant 0 \cdot 001$. 
each respiratory symptom were not significant. Significant differences in the prevalence of all conditions were found among the ethnic groups $(\mathbf{p}<0.05)$ after allowance was made for the effects of the independent variables. These results were similar to those for the unadjusted prevalences and are illustrated in table III adjusted to boys aged 8 with a mother with secondary school education and with one sibling.

The second set of regression analyses, conducted in 2022 whites and 530 Afro-Caribbeans, studied additionally the effects of belonging to a one parent family and of living in a home in which gas cookers or paraffin heaters were used. Table IV gives the relative risk of respiratory conditions associated with mother's education, number of children in the family, belonging to a one parent family, and use of gas cookers and paraffin heaters. Results for asthma and bronchitis showed no significant relation to any of these factors and are not shown. High risks of all the conditions shown in table IV were associated with one parent families compared with two parent families $(p<0.05)$. The risk of respiratory illness increased when two or more sources of nitrogen dioxide (a gas cooker and paraffin heaters) were present in the home. The association between gas cookers alone and respiratory illness approached significance for cough in the morning and wheeze $(p<0 \cdot 1)$. The association between respiratory illness and the combined use of a gas cooker and paraffin heaters was significant for colds going to the chest and the presence of one or more respiratory conditions $(p<0.05)$. For a subset of 2164 whites and Afro-Caribbeans regression analysis of each respiratory condition was conducted to include father's social class and uptake of free school meals. The effects on respiratory illness of one parent families and the combined use of gas cookers and paraffin heaters remained significant for colds going to the chest $(p<0.05)$ and borderline for the overall measure $(p=0.052)$.

To assess further the problem of respiratory illness in inner cities the prevalence of respiratory conditions in the 1983 sample of white children was compared with the prevalence in the 1982 national representative sample after allowance had been made for the effects of interfering variables. The prevalences of cough in the morning, cough during the day or night, wheezing, and bronchitis were significantly higher in 1983 than 1982 $(\mathrm{p}<0 \cdot 05)$.

\section{Discussion}

In our study Afro-Caribbeans and white people living in inner cities had higher prevalences of several conditions compared with Asians. In a national cohort of children the prevalence of wheezing was significantly higher in children with West Indian and British parents than those with Asian parents $(\mathrm{p}<0.01)$, but the prevalence of asthma and bronchitis did not differ among ethnic groups. ${ }^{12}$ West Indian' and Bengali' infants have been reported to attend accident and emergency departments because of respiratory disease more commonly than white children, but this may partly reflect a different pattern of use of health services by ethnic groups. Smith found asthma and wheezing in 5-6 year olds to be more prevalent in West Indians born in England than in Asians born in England or abroad. ${ }^{4}$ It is unclear, however, which groups of Asians were being studied. In our study the prevalence of asthma differed among groups of Asians.

The differing results of studies may be explained partly by differences in methodology and partly by biases in the results. Three main biases should be considered. Firstly, certain ethnic groups such as Punjabis are not homogeneous, and subgroups would be expected to differ in health. The distribution of these subgroups varies in England, and a study in one area is likely to contain only one subgroup. Each ethnic group in our study lived in several areas of England, so our results cover a range of children within each group. Secondly, respiratory illness may well be perceived differently by each ethnic group, and these differences may not have been dealt with simply by translating the questionnaire. Although studies of the incidence and prevalence of respiratory disease indicate the burden of respiratory disease experienced by some groups, objective measures of respiratory ill health, such as lung function, would contribute further to the study of respiratory illness in ethnic groups. Thirdly, in this study response rates varied among ethnic groups even though non-responders were followed up by health visitors and the questionnaire was available in three languages. Inclusion of non-responders known to have respiratory illness, however, made no difference to our results. The relation of respiratory illness to factors such as age was similar to previous findings, which gives some credence to our results.

A raised prevalence of respiratory illness might be expected in large families ${ }^{13}$ and when the mother's educational level is low, this being associated with poor social class,,${ }^{14}$ but such was not the case in this study. Single children had significantly more colds going to the chest and more wheezing $(p<0.05)$ than children with three or more siblings. A mother with only one child to care for may be more aware of that child developing respiratory illness than mothers with larger

TABLE III-Mean prevalence (expressed as percentage (and number)) of respiratory conditions adjusted to boys aged 8 with mother educated up to secondary school and two children in family. Figures in each group are for the 1983 sample

\begin{tabular}{|c|c|c|c|c|c|c|c|c|}
\hline & $\begin{array}{c}\text { White } \\
(n=2105)\end{array}$ & $\begin{array}{l}\text { Afro-Caribbean } \\
\quad(n=545)\end{array}$ & $\underset{(n=323)}{\text { Urdu }}$ & $\begin{array}{l}\text { Gujarati } \\
(n=441)\end{array}$ & $\begin{array}{l}\text { Punjabi } \\
(n=887)\end{array}$ & $\begin{array}{l}\text { Other Asian } \\
(n=218)\end{array}$ & $\begin{array}{c}\text { Other } \\
(n=296)\end{array}$ & $\begin{array}{c}\text { Total } \\
(n=4815)\end{array}$ \\
\hline Cough in morning & $4 \cdot 4(158)$ & $5.9(51)$ & $3 \cdot 2(23)$ & $2 \cdot 7(24)$ & $2 \cdot 6(62)$ & $3 \cdot 7(16)$ & $2 \cdot 5(13)$ & $5 \cdot 5(347)^{\star}$ \\
\hline Cough during day or night & $14 \cdot 4(324)$ & $15 \cdot 8(95)$ & $6.9(30)$ & $7 \cdot 3(41)$ & $6 \cdot 3(82)$ & $8 \cdot 3(23)$ & $6.8(21)$ & $10 \cdot 4(616)^{\star \star}$ \\
\hline Wheezing & $11 \cdot 7(287)$ & $10.8(73)$ & $8 \cdot 7(36)$ & $5 \cdot 3(25)$ & $5 \cdot 7(78)$ & $4 \cdot 8(14)$ & $7 \cdot 3(24)$ & $8 \cdot 8(537)^{\star \star}$ \\
\hline "Colds going to chest" & $36 \cdot 7(704)$ & $34 \cdot 4(174)$ & $20 \cdot 8(56)$ & $17 \cdot 1(66)$ & $18 \cdot 7(161)$ & $26.9(51)$ & $28 \cdot 3(72)$ & $24 \cdot 3(1284)^{\star \star}$ \\
\hline Bronchitis & $11 \cdot 6(138)$ & $4 \cdot 6(21)$ & $1.9(3)$ & $2.6(6)$ & $6.7(30)$ & $5 \cdot 1(6)$ & $6.0(9)$ & $4.4(213)^{\star \star}$ \\
\hline Asthma & $3 \cdot 1(49)$ & $2 \cdot 2(10)$ & $7 \cdot 0(16)$ & $1.5(6)$ & $5 \cdot 0(32)$ & $4.9(9)$ & $6.0(14)$ & $3 \cdot 4(136)^{\star}$ \\
\hline One or more respiratory conditions & $46 \cdot 1(833)$ & $46 \cdot 1(220)$ & $32 \cdot 8(85)$ & $25 \cdot 7(93)$ & $28 \cdot 7(229)$ & $34 \cdot 6(62)$ & $37 \cdot 5(92)$ & $35 \cdot 6(1614)^{\star \star}$ \\
\hline
\end{tabular}

${ }^{\star} \mathrm{p}<0.05,{ }^{\star \star} \mathrm{p}<0.001\left(\chi^{2}\right.$ test, $\left.\mathrm{df}=6\right)$ After allowing for effects of age, sex, mother's educational attainment, number of children in family, and area of residence.

TABLE IV-Relative risk ${ }^{\star}$ (95\% confidence intervals) of respiratory conditions in Afro-Caribbean and white children (1983 data; $\left.n=2552\right)$ associated with characteristics of family and home

\begin{tabular}{|c|c|c|c|c|c|c|}
\hline & No of children & Cough in morning & Cough during day or night & Wheezing & "Colds going to chest" & One or more respiratory conditions \\
\hline \multicolumn{7}{|l|}{ Mother's education: } \\
\hline No formal education or elementary & 196 & $2 \cdot 15+(1 \cdot 4$ to $3 \cdot 28)$ & $1.42+(1.04$ to 1.89$)$ & $1.33(0.95$ to 1.83$)$ & $1 \cdot 11(0.92$ to 1.31$)$ & $1.17(1.0$ to 1.33$)$ \\
\hline College or university & 366 & $0.81(0.5$ to 1.31$)$ & $0.67+(0.47$ to 0.93$)$ & $1.21(0.91$ to 1.53$)$ & $0.88(0.75$ to 1.04$)$ & $0.88(0.75$ to 1.00$)$ \\
\hline \multicolumn{7}{|l|}{ No of children in family: } \\
\hline 2 & 902 & $1.54(0.86$ to 2.73$)$ & $1.05(0.75$ to 1.46$)$ & $0.74(0.52$ to 1.02$)$ & $0.83+(0.68$ to 0.99$)$ & $0.84+(0.70$ to 0.99$)$ \\
\hline 3 & 699 & $1.82(1.0$ to 3.23$)$ & $1.22(0.87$ to 1.68$)$ & $0.89(0.63$ to 1.23$)$ & $0.85(0.69$ to 1.02$)$ & $0.90(0.76$ to 1.06$)$ \\
\hline$\geqslant 4$ & 668 & $1.75(0.97$ to 3.13$)$ & $1.07(0.75$ to 1.49$)$ & $0.65+(0.45$ to 0.93$)$ & $0.70+(0.56$ to 0.86$)$ & $0.77+(0.63$ to 0.92$)$ \\
\hline One parent family & 805 & $1.48+(1.07$ to 2.03$)$ & $1.49+(1.22$ to 1.8$)$ & $1.27 \dagger(1.02$ to 1.56$)$ & $1.16+(1.04$ to 1.28$)$ & $1.18+(1.08$ to 1.28$)$ \\
\hline \multicolumn{7}{|l|}{ Cooking and heating fuels: } \\
\hline Gas cookers, no paraffin heaters & 1964 & $1.48(0.97$ to 2.24$)$ & $0.93(0.73$ to 1.19$)$ & $1.27(0.98$ to 1.64$)$ & $1 \cdot 10(0.97$ to 1.24$)$ & $1.06(0.94$ to 1.17$)$ \\
\hline Gas cookers, paraffin heaters & 83 & $1.85(0.79$ to 4.25$)$ & $1.14(0.64$ to 1.90$)$ & $1.64(0.94$ to 2.63$)$ & $1.40+(1.08$ to 1.71$)$ & $1.35+(1.09$ to 1.59$)$ \\
\hline
\end{tabular}

*Relative to risk in white boys aged 8 with mother educated up to secondary school, one child in family, two parent family, and no gas or paraffin fuels used in the home.

†Difference from relative risk of $1 \cdot 0: p<0 \cdot 05$. 
families to look after. A low educational level of the mother was associated only with a high prevalence of cough $(p<0.05)$. It may be inappropriate to compare educational background of ethnic groups, particularly those educated abroad, as educational categories may not be directly comparable.

Two other factors previously associated with respiratory illness in children-namely, belonging to a one parent family ${ }^{15}$ and exposure to indoor air pollution from gas cookers and paraffin heaters ${ }^{11} 16{ }^{17}$ could be studied only in Afro-Caribbeans and whites. Belonging to a one parent family is likely to measure poor social circumstances, but a single parent may be more aware of a child developing respiratory illness. The association of respiratory illness with the combined use of gas cookers and paraffin heaters might reflect poor social circumstances as well as high concentrations of nitrogen dioxide indoors, which may sometimes exceed the European Community's directive for outdoor concentrations of nitrogen dioxide. ${ }^{18}$ Parental smoking habit was not analysed, though smoking has been reported to be more common among Afro-Caribbeans and whites than Asians. ${ }^{12}$

This survey highlights the problem of respiratory disease in children living in inner cities. Such disease was significantly more prevalent in whites compared with all groups in the national sample and varied considerably among ethnic groups. Strong evidence suggests that childhood respiratory illness leads to poor respiratory health in adulthood. ${ }^{6}$ We intend to study the variation in respiratory illness among ethnic groups further.

We thank Professor W W Holland for his encouragement and the doctors, nurses, teachers, clerks, and fieldworkers in the national study of health and growth for their help. This study was supported by grants from the Department of Health and Social Security and the Scottish Home and Health Department.

\section{References}

1 Oppé TE. The health of the coloured child in Great Britain. Proceedings of the Royal Society of Medicine 1964;57:321-3.

2 Black J. The difficulties of living in Britain. BrMed f 1985;290:615-7.

3 Hood C. Social and cultural factors in health of children of immigrants. Arch Dis Child 1971;46:371-5.

4 Smith JM. The prevalence of asthma and wheezing in children. Br $\mathcal{F}$ Dis Chest 1976;70:73-7.

5 Watson E. Health of infants and use of health services by mothers of different ethnic groups in east London. Community Med 1984;6:127-35.

6 Britten N, Davies JMC, Colley JRT. Early respiratory experience and subsequent cough and peak expiratory flow rate in 36 year old men and women. Br Med $\mathcal{F}$ 1987;294:1317-20.

7 Rona RJ, Chinn S. National study of health and growth: social and biological factors associated with height of children from ethnic groups living in England. Ann Hum Biol 1986;13:453-71.

8 Rona RJ, Chinn S, Florey CV. Exposure to cigarette smoking and children's growth. Int $\mathfrak{f}$ Epidemiol 1985;14:402-9.

9 Baker RJ, Nelder JA. The GLIM system (release 3) generalized linear interactive modelling. Oxford Numerical Algorithms Group, 1978.

10 Collins JJ, Kasap HS, Holland WW. Environmental factors in child mortality in England and Wales. Am f Epidemiol 1971;93:10-22.

11 Goldstein BD, Melia RJW, Chinn S, Florey CV, Clark D, John HH. The relation between respiratory illness in primary school children and the use of gas for cooking. II. Factors affecting nitrogen dioxide levels in the home. Int $f$ Epidemiol 1979;8:339-45.

12 Butler NR, Golding J. From birth to five. Oxford: Pergamon Press, 1986.

13 Leeder SR, Corkhill R, Irwig LM, Holland WW, Colley JRT. Influence of family factors on the incidence of lower respiratory illness during the first year of life. British fournal of Preventive and Social Medicine 1976;30:203-12.

14 Reid I. Social class differences in Britain. 2nd ed. London: Grant McIntyre, 1981.

15 Jennings AJ, Sheldon MG. Review of the health of children in one-parent families. $f R$ Coll Gen Pract 1965;35:478-83.

16 Atkins DHF, Healy C, Tarrant JB. The measurement of nitrogen dioxide levels associated with domestic paraffin convector heaters. Harwell: Atomic Energy Research Establishment, 1980.

17 Melia RJW, Florey CV, Chinn S. The relation between respiratory illness in primary schoolchildren and the use of gas for cooking. I-Results from a national survey. Int $\mathcal{F}$ Epidemiol 1979;8:333-8.

18 Council of the European Communities. Council directive of 7 March 1985 on air quality standards for nitrogen dioxide. Official foumal of the European Communities: Legislation 1985;28:L87/1-7. (English ed.)

(Accepted 18 fanuary 1988)

\section{SHORT REPORTS}

\section{Is surgical closure of the back lesion in open neural tube defects necessary?}

Early closure of the lesion is believed to be central to the management of open neural tube defects. ${ }^{1}$ Non-closure of the defect, however, does not necessarily increase morbidity to mortality. ${ }^{23}$ Since 1978 open neural tube defects in patients with a poor prognosis have not been closed at our unit, but the patients have received full medical and nursing care, including antibiotics and shunts for hydrocephalus when necessary. We compared these patients with an earlier group who had received early closure as an urgent treatment.

\section{Patients, methods, and results}

We reviewed patients with open neural tube defects above $L 2$ or hydrocephalus at birth, or both. Altogether 109 had been born between 1964 and 1971 and 105 born between 1978 and 1985 . Treatment policies differed only in that children born between 1964 and 1971 had received early closure of the defect whereas for children born between 1978 and 1985 closure had not been performed or had been deferred until they were at least 3 months old. Data were analysed with the statistical package for the social sciences life tables and the Lee-Desu statistic. Patients who died before they developed a complication were included as "censored" data. Mortality and the incidence of hydrocephalus, insertion of a shunt, ventriculitis, and ventriculitis before insertion of a shunt were compared by relating the difference at any time to the standard error of the difference expressed as a standardised normal $\mathrm{z}$ statistic.

No significant difference in the sex ratio, number of children born with hydrocephalus, or number of children with a neurological level above L2 was found between the two groups. The table shows that non-closure resulted in a significantly lower incidence $(p<0.001)$ of hydrocephalus, insertion of a shunt, ventriculitis, and ventriculitis before insertion of a shunt during the first few months of life but did not affect mortality throughout the first year. After the first year there was no significant difference in any of the complications between the groups.

Hydrocephalus correlated with ventriculitis $(\mathrm{p}<0.001)$ during the first year; among those whose wound was not closed 37 of the 72 patients with hydrocephalus developed ventriculitis compared with six of the 37 without hydro-
Cumulative survival and proportions (SE) of babies with open neural tube defects without the complications specified at one, three, six, and 12 months

\begin{tabular}{|c|c|c|c|c|}
\hline & \multicolumn{4}{|c|}{ Months from birth } \\
\hline & 1 & 3 & 6 & 12 \\
\hline \multicolumn{5}{|l|}{ Survival: } \\
\hline Early closure & $0.86(0.03)$ & $0.78(0.04)$ & $0.65(0.05)$ & $0.51(0.05)$ \\
\hline Non-closure & $0.81(0.04)$ & $0.73(0.04)$ & $0.64(0.05)$ & $0.50(0.05)$ \\
\hline \multicolumn{5}{|c|}{ Without hydrocephalus: } \\
\hline Early closure & $0.40(0.07)^{\star}$ & $0.12(0.05)^{\star}$ & $0.08(0.05)^{\star}$ & $0.08(0.05)$ \\
\hline Non-closure & $0.83(0.05)$ & $0.46(0.07)$ & $0.25(0.06)$ & $0.10(0.05)$ \\
\hline \multicolumn{5}{|l|}{ Without a shunt: } \\
\hline Early closure & $0.64(0.05)^{\star}$ & $0.18(0.05)^{\star}$ & $0.13(0.04)^{\star}$ & $0.11(0.04)$ \\
\hline Non-closure & $0.76(0.05)$ & $0.51(0.05)$ & $0.29(0.05)$ & $0.13(0.04)$ \\
\hline \multicolumn{5}{|c|}{ Without ventriculitis: } \\
\hline Early closure & $0.84(0.04)^{\star}$ & $0.64(0.05)^{\star}$ & $0.58(0.05)$ & $0.48(0.06)$ \\
\hline Non-closure & $0.94(0.03)$ & $0.78(0.04)$ & $0.69(0.05)$ & $0.48(0.06)$ \\
\hline \multicolumn{5}{|c|}{ Without ventriculitis before } \\
\hline Early closure & $0.72(0.05)^{\star}$ & $0.69(0.06)$ & $0.66(0.06)$ & $0.66(0.06)$ \\
\hline Non-closure & $0.90(0.06)$ & $0.85(0.07)$ & $0.75(0.09)$ & $0.75(0.09)$ \\
\hline
\end{tabular}

*Significance of difference between groups $\mathrm{p}<0.001$

cephalus, and similar results were found for the babies who received early closure.

\section{Comment}

We are aware of the caution necessary in analysing historical data Nevertheless, the finding that mortality did not increase when the neural tube lesion was not closed implies, contrary to previous belief, that early closure as an urgent procedure is not essential for an optimal prognosis. Similarly, the incidence of ventriculitis and, more importantly, of ventriculitis before shunting was reduced during the first three months by non-closure of the defect, suggesting that early closure may not be necessary to reduce the risk of ascending infection.

The incidence of both hydrocephalus and insertion of a shunt was 